\title{
INCLUSÃO FINANCEIRA E VULNERABILIDADE DO CONSUMIDOR DE CRÉDITO HABITACIONAL: UMA ANÁLISE JURÍDICO-ECONÔMICA DO MERCADO BRASILEIRO
}

\author{
Ana Elizabeth Neirão Reymão* \\ Felipe Guimarães de Oliveira**
}

\section{RESUMO}

O artigo objetiva discutir a vulnerabilidade do consumidor de crédito imobiliário oportunizada pela inclusão financeira, pela grande liquidez desse mercado e pela política habitacional brasileira recente. Efetua-se uma análise jurídico-econômica, de abordagem qualitativa e quantitativa, e constata-se que a vulnerabilidade do consumidor, aliada ao sonho da casa própria, ao assédio de consumo e a sagacidade do mercado, facilita a prática de inúmeros ilícitos de consumo por parte de alguns fornecedores de crédito, o que não pode ser admitido nesta quadra da história. O crédito tomado precisa ter qualidade, ter transparência, uma dimensão fundamental da cidadania financeira.

Palavras-chave: Crédito Imobiliário; Inclusão Financeira; Defesa do Consumidor; Vulnerabilidade.

\section{FINANCIAL INCLUSION AND CONSUMER VULNERABILITY IN HOUSING CREDIT: A LEGAL AND ECONOMIC ANALYSIS OF THE BRAZILIAN MARKET}

\begin{abstract}
This paper discusses the consumer vulnerability of real estate credit linked to financial inclusion, market liquidity and the recent Brazilian housing policy. It's a legal-economic analysis that uses qualitative and quantitative approach and concludes that consumer vulnerability, in association with the dream of home, consumption seat and market wit, facilitates the practice of many consumer illicit acts by some credit providers, which can not be actually admitted. Credit must have quality, transparency, a fundamental dimension of financial
\end{abstract}

\footnotetext{
* Economista, professora da Faculdade de Economia da Universidade Federal do Pará (UFPA) e do Programa de Pós-Graduação em Direito do Centro Universitário do Pará (CESUPA). E-mail: bethrey@uol.com.br

** Mestre em Direito pelo Centro Universitário do Pará (CESUPA), instituição da qual também é Professor de Direito do Consumidor e Direito Econômico na Graduação e Coordenador-geral da Clínica Superendividamento. Advogado. E-mail:fguima.oliveira@hotmail.com
} 
citizenship.

Keywords: Real Estate Credit; Financial Inclusion; Consumer Defense; Vulnerability.

\section{INTRODUÇÃO}

O presente artigo objetiva discutir a vulnerabilidade do consumidor de crédito imobiliário oportunizada pela inclusão financeira, pela grande liquidez desse mercado e pela política habitacional no Brasil na última década.

Até 2014 o Brasil experimentou políticas que advogavam o crescimento econômico com inclusão social e melhoria da distribuição de renda à população, pautadas na valorização do poder de compra do salário mínimo e em transferências condicionadas de rendas. Uma consequência positiva dessas políticas foi a maior participação do crédito na composição do produto interno bruto (PIB) e o aumento dos serviços financeiros acessíveis à população.

O crescimento dos serviços financeiros vivenciado pelo país foi acompanhado por uma substancial elevação do crédito, que representava 54,8\% do PIB em março de 2015, muito superior ao registrado últimos trinta anos: com Collor (1990-1992), seu percentual mais elevado foi de $28 \%$ e nos governos FHC foi 37\%, no auge do Plano Real (1995), ficando em 34\% em 2007 (RIBEIRO; LARA, 2016).

Um dos créditos que mais se expandiram foi o crédito imobiliário que, em 2014, representava a principal modalidade de crédito para as famílias, significando quase $1 / 3$ do crédito do sistema financeiro nacional $(31 \%)$.

Com isso, o mercado imobiliário brasileiro experimentou um boom após 2008, levando ao surgimento de novas incorporadoras e construtoras pois, diferentemente do que ocorria nos Estados Unidos, aqui havia uma expansão de vagas de trabalho, do crédito e dos estímulos para a aquisição da primeira casa própria.

A participação do Estado na economia brasileira foi fundamental para viabilizar esse aumento, pois além das políticas de elevação do poder de compra das camadas mais baixas da população, a resposta do governo à crise internacional de 2008 foi marcada pela intensificação do uso de medidas expansionistas na área fiscal e monetária.

Além da redução da taxa de juros básica da economia, o governo estimulou a elevação dos recursos direcionados do mercado de crédito, com alta participação dos bancos públicos no total de empréstimos concedidos pelo sistema financeiro. Incentivou o crédito para a aquisição 


\section{INCLUSÃO FINANCEIRA E VULNERABILIDADE DO CONSUMIDOR DE CRÉDITO HABITACIONAL: UMA ANÁLISE JURÍDICO-ECONÔMICA DO MERCADO BRASILEIRO}

de bens-veículos, uma das modalidades mais afetadas pela crise, por meio da redução das alíquotas do Imposto sobre Produtos Industrializados (IPI) para a compra de automóveis.

Em 2009, com o lançamento do Programa Minha Casa Minha Vida (PMCMV), incentivou a construção civil e assumiu a maior parte da oferta de habitação de interesse social do país, voltada ao atendimento das famílias de baixa renda.

Tais medidas foram muito importantes para recuperação da economia brasileira. Porém, a aceleração da inflação, o mau desempenho da balança comercial brasileira e a baixa competitividade dos produtos nacionais em fins de 2010 levaram o recém eleito governo da presidente Dilma Rousseff a adotar algumas medidas restritivas, com cortes de gastos e ações para reduzir a expansão do crédito.

Os financiamentos habitacionais, no entanto, não foram atingidos por medidas restritivas e suas taxas de juros permaneceram baixas. Em 2013, foram introduzidos incentivos à aquisição de bens duráveis por meio do programa Minha Casa Melhor, destinado aos beneficiários do MCMV.

Além da disponibilidade de crédito e da facilidade de acesso aos serviços financeiros para um enorme contingente de brasileiros que não tinham casa própria, contribuiu para a expansão desses financiamentos estratégias de vendas pautadas em uma grande publicidade, jamais vista no país, orientada especialmente para os consumidores mais vulneráveis, quais sejam, idosos, analfabetos, induzindo-os ao crédito. Não raro foram relatadas práticas abusivas, ferindo os direitos desses consumidores.

Para discutir a vulnerabilidade desse consumidor oportunizada pela inclusão financeira, pela grande liquidez do mercado de crédito e pela política de crédito habitacional no Brasil na última década, já anunciada como objetivo desse artigo, realizou-se um levantamento bibliográfico e documental sobre o tema. Foram consultados relatórios e documentos do Banco Central do Brasil sobre a dinâmica do mercado financeiro e a política econômica do período. Dados sobre o financiamento imobiliário e o endividamento dos consumidores de crédito e foram sistematizados. Também foi consultada a jurisprudência do Superior Tribunal de Justiça (STJ) que versa sobre práticas abusivas efetivadas por fornecedores de serviços imobiliários.

Essa análise jurídico-econômica, de abordagem qualitativa e quantitativa, é apresentada em um texto estruturado em quatro partes. Depois dessa introdução, a seção dois dedica-se ao estudo da inclusão financeira e do crescimento do crédito no país. A seção três discute a vulnerabilidade do consumidor de crédito imobiliário e sua relação com o desejo da 
casa própria, prejudicado pelo déficit habitacional brasileiro. Por fim, a seção quatro apresenta as considerações finais e as conclusões sobre a pesquisa.

\section{CRESCIMENTO DO CRÉDITO E INCLUSÃO FINANCEIRA NO BRASIL}

Até 2014, as medidas de política econômica brasileira promoveram a expansão do mercado interno, tendo o período também sido marcado por forte atuação do Estado e por medidas para reduzir a desigualdade na distribuição de renda do país.

O período que se iniciara em 2003 marcaria, relatam Reymão e Oliveira (2016), a implantação de um modelo novo desenvolvimentista, expressão utilizada por autores como Nelson Barbosa (2013), João Sicsú e Armando Castelar (2009), Luiz Gonzaga Belluzzo (2015), Emir Sader (2015), Jorge Mattoso (2015) e Luiz Carlos Bresser-Pereira (2006) e outros para conceituar a política econômica iniciada na gestão do presidente Lula. Esse novo modelo de desenvolvimento objetivava estimular o crescimento e desenvolvimento nacional, acompanhado de uma política distributiva.

Seu principal desafio seria superar o fracasso do neoliberalismo das políticas anteriores no que diz respeito à promoção do crescimento econômico do país: em 1998, a taxa de crescimento do produto interno bruto (PIB) era apenas de $0,1 \%$ aa, tendo o PIB per capita crescido apenas 1\% entre 1992 e 1994 (Itamar Franco) e de 1995 a 2002 (Fernando Henrique Cardoso), como evidenciam os dados do Banco Central do Brasil.

Uma das principais críticas era quanto ao quadro de desigualdades sociais herdado do governo anterior, marcado por um elevado percentual de pessoas vivendo abaixo da linha de pobreza extrema: 27,26\% em 2003, segundo dados da Pesquisa Nacional por Amostra de Domicílios (PNAD).

Dessa forma, as medidas propagadas pelo Consenso de Washington e pela ortodoxia convencional e implantadas nos governos Collor e FHC, a partir dos anos 1990, como disciplina fiscal, priorização dos gastos públicos, reforma tributária, liberalização financeira, cambial e comercial, investimento direto estrangeiro, privatização e desregulação, trouxeram a estabilidade monetária, é verdade, mas também uma aguda recessão e agravamento de problemas sociais no país, quadro que só mudou após o primeiro governo novo desenvolvimentista (REYMÃO; OLIVEIRA, 2016). 


\section{INCLUSÃO FINANCEIRA E VULNERABILIDADE DO CONSUMIDOR DE CRÉDITO HABITACIONAL: UMA ANÁLISE JURÍDICO-ECONÔMICA DO MERCADO BRASILEIRO}

Na publicação "Novo Desenvolvimentismo: um projeto nacional de crescimento com equidade social", obra organizada por professores do Instituto de Economia da UFRJ, os autores definiam como centrais para um novo projeto de desenvolvimento:

1) a existência de um Estado forte e de um mercado forte também; 2) a implementação de políticas macroeconômicas que fortaleçam essas duas instituições; 3) a adoção de uma estratégia nacional de desenvolvimento que compatibilize crescimento econômico com equidade social; e 4) a manutenção de taxas de crescimento em patamares elevados para reduzir as desigualdades sociais (MATTEI, 2013, p. 49).

Prometendo alcançar esses objetivos, o país experimentou uma fase de aumento da intervenção do Estado na economia e, até 2008, verificou-se a recuperação do produto interno bruto (PIB), uma redução das disparidades de renda, da pobreza e elevação da geração de empregos. Contribuíram para esses resultados a estabilidade macroeconômica, uma conjuntura internacional favorável e políticas sociais inovadoras para reduzir a pobreza e assegurar a inclusão de grupos até então excluídos, que tiraram muitos brasileiros da extrema pobreza e da insegurança nutricional.

Como parte das políticas adotadas, em prol da inclusão social e melhoria da distribuição de renda a população, destacam-se a de valorização do poder de compra do salário mínimo e as de transferências condicionadas de rendas, como o Bolsa Família, o principal programa de combate à pobreza do governo federal ${ }^{1}$.

Uma consequência importante da política econômica e social do período foi uma maior participação do crédito na composição do PIB e o aumento dos serviços financeiros acessíveis à população.

Tal aumento pode ser medido por indicadores diversos, um deles é a quantidade de pontos de atendimento (agência, posto de atendimento, posto de atendimento eletrônico e correspondente), que cresceu muito, de maneira que quase todos os 5.570 municípios brasileiros contavam com pelo menos $\mathrm{um}^{2}$.

\footnotetext{
${ }^{1}$ O programa Bolsa Família foi lançado em 2003 e, para promoção do alívio imediato da pobreza, caracteriza-se pela concessão de uma transferência direta de renda a famílias em situação de vulnerabilidade social, além de outras ações complementares. Em 2006 atingiu sua meta inicial de atendimento, de cerca de 11 milhões de famílias beneficiárias em 2006. De 2012 a 2015, o número de famílias beneficiadas ficou em torno de 14 milhões. Dados do Ministério do Desenvolvimento Social mostram que o valor médio do benefício aumentou de R\$72,33 para $\mathrm{R} \$ 150,27$ em 2014 (quase 108\%), equivalendo um ganho real próximo a $26 \%$.

${ }^{2}$ Em 2014, somente Pescaria Brava (SC), criado em 2013, não tinha ponto de atendimento.
} 
Outro indicador é o aumento do número de municípios com mais de quinze pontos de atendimento para cada grupo de 10 mil adultos: de 3.254 para 4.048 entre 2010 e 2014 . Pode também ser notada queda da quantidade de municípios com 2 a 8 pontos: de 631 para 233, mostra o Relatório de Inclusão Financeira do Banco Central (2015).

Em termos regionais, esse avanço também é percebido: a região Norte, a menos servida por pontos de atendimento, verificou crescimento significativo na dimensão geográfica, de 11,12 para 12,96, no número de pontos por 10 mil adultos, além do aumento, de 3,20 para 4,03 , nos pontos por $\mathrm{km}^{2}$. Apesar desse crescimento da região, o Norte ainda fica bem atrás do Sul e Sudeste. Nessa região, por exemplo, o número de pontos por 10 mil adultos subiu de 18,94 para 19,23; já os pontos por $\mathrm{km}^{2}$ se elevaram de 128,9 para 139,32, mostra o mesmo relatório.

Dentre os pontos de atendimento, as agências (24\%) e points of sale (POSs) $(45,8 \%)$ tiveram aumento significativo entre 2010 e 2014, outros, como os postos de atendimento eletrônicos (PAEs) $(6,6 \%)$ e correspondentes $(6 \%)$, tiveram crescimento menos expressivo. Essa expansão do acesso foi maior entre 2005 e 2010 (11\% aa) que no período 2010-2014 (2\%), mas embora o ritmo tenha sido menor, o aumento concentrou-se em municípios menores, ainda pouco atendidos (BANCO CENTRAL, 2015).

Cumpre destacar o número de instalações de correspondentes ${ }^{3}$ no país, que vinha crescendo rapidamente até 2008, elevando-se de 20 mil em 2000 para quase 130 naquele ano, contribuindo para que quase todos os municípios tenham acesso a serviços bancários (LOUREIRO; MADEIRA; BADER, 2016). Nos anos seguintes, como já afirmado, essa expansão foi menor, mas ainda importante.

Quanto ao uso, observou-se um crescimento nos canais remotos (não presenciais), como internet, celulares e tablets. Assim, a partir de 2014 tem-se uma inversão na preferência, com maior utilização desses canais, em especial do internet banking e dos dispositivos remotos. Interessante notar que em 2010 somente 61 milhões das mais de 31 bilhões $(0,2 \%)$ das operações financeiras realizadas no Brasil foram com telefones celulares e tablets (wireless).

\footnotetext{
${ }^{3}$ Os correspondentes bancários são usados tanto por bancos públicos como privados para, em geral, viabilizar sua atuação em regiões sem escala suficiente para a abertura de uma agência. Loureiro, Madeira e Bader (2016) lembram que a infraestrutura necessária para a atuação de um correspondente é significativamente menor que a de uma agência. Podem utilizar a estrutura física do estabelecimento e os regulamentos de segurança são menos rigorosos. Os funcionários não atuam exclusivamente para esse serviço, nem precisam estar ligados a um sindicato. Ainda assim, cumpre destacar que a presença dos correspondentes não é restrita a regiões remotas ou de baixa população. Os municípios com o maior número de correspondentes são Rio de Janeiro (acima de 4000) e São Paulo (acima de 8000).
} 


\section{INCLUSÃO FINANCEIRA E VULNERABILIDADE DO CONSUMIDOR DE CRÉDITO HABITACIONAL: UMA ANÁLISE JURÍDICO-ECONÔMICA DO MERCADO BRASILEIRO}

Em 2014 esse número já era superior a 5 mil, correspondendo a mais de $10 \%$ das operações, uma taxa média anual de crescimento de $202,4 \%$ entre 2010 e 2014 . A facilidade de acesso e o aumento da segurança dos canais de atendimento não presenciais contribuíram para aumento das transações por essas vias, explica o citado Relatório.

Todo esse crescimento dos serviços financeiros foi acompanhado por um expressivo aumento do crédito na última década, especialmente para as famílias. O peso do crédito no PIB era de 54,8\% em março de 2015, um salto nos últimos trinta anos: na era Collor (1990-1992) o pico foi de 28\%, nos governos FHC alcançou 37\%, no ápice do Plano Real (1995), e em 2007 era de $34 \%$ (RIBEIRO; LARA, 2016).

Chama atenção que, após a retomada da atividade econômica em 2010, impactada pela crise internacional de 2008, e com a melhora dos indicadores de emprego e renda, o volume de crédito tenha aumentado significativamente: $82 \%$ entre 2010 e 2014. No ano dessa retomada ele havia crescido $21 \%$, impulsionado pelos financiamentos de veículos e imobiliários (BANCO CENTRAL, 2015).

Esse aumento está intimamente ligado à resposta do governo à crise internacional e a intensificação da política expansionista na área fiscal e monetária, explicam Reymão e Oliveira (2016): redução da taxa Selic (mantida em 8,75\% entre julho de 2009 e março de 2010), elevação dos recursos direcionados (de cerca de $12 \%$ para $14,6 \%$ do PIB), além da alta participação dos bancos públicos no total de crédito concedido pelo sistema financeiro (crescimento de 36,3\% em 2008 para 41,5\% em 2009).

Outro fator importante foi a manutenção da política de rendas: “apesar da queda das receitas do governo, a política de rendas foi mantida, com os reajustes do salário mínimo, aumento das transferências e elevação das despesas com a previdência social, o abono salarial e o seguro-desemprego" (REYMÃO; OLIVEIRA, 2016, p. 29).

Para o aumento dos investimentos, o governo lançou o Programa de Aceleração do Crescimento (PAC), focando na área de transportes e logística e no investimento da Petrobras na exploração e produção de petróleo. Em 2009, lançou o Programa Minha Casa Minha Vida $(\mathrm{PMCMV})^{4}$, que incentivou a construção civil e assumiu a maior parte de provisão habitacional

\footnotetext{
${ }^{4} \mathrm{O}$ PMCMV trazia uma proposta social, com inovações na política habitacional brasileira voltada às famílias de baixa renda. Foi lançado em 2009 como parte das medidas anticíclicas adotadas pelo governo diante da crise econômica internacional. Foram firmadas parcerias com governos estaduais e municipais e usados recursos do Orçamento Geral da União (OGU) e do Fundo de Garantia por Tempo de Serviço (FGTS). Para estimular a compra da unidade habitacional, houve a redução da taxa de juros, uma menor burocratização na compra e outros subsídios
} 
de interesse social do país, visando às famílias de baixa renda. Dentre seus objetivos, o PMCMV pretendia reduzir o déficit habitacional no país, além de estimular o crescimento de um setor muito intensivo em trabalho e pouco intensivo em importações como instrumento de geração de emprego e renda, a construção civil (BARBOSA, 2013).

Também fizeram parte do pacote de medidas anticíclicas um conjunto de desonerações tributárias para estimular o consumo e o investimento, como a redução das alíquotas do Imposto sobre Produtos Industrializados (IPI) para a compra de automóveis ${ }^{5}$, cuja produção acumulava um elevado estoque involuntário no final de 2008. Com esse incentivo, o crédito para a aquisição de bens-veículos, uma das modalidades mais afetadas pela crise, voltou a crescer.

Apesar de essas medidas terem ajudado na recuperação da economia brasileira, a aceleração da inflação, o mau desempenho da balança comercial brasileiro e a baixa competitividade da economia brasileira em fins de 2010 levaram a presidente Dilma, no início de seu governo, a adotar algumas medidas restritivas, com contingenciamento de gastos públicos, redução dos investimentos em infraestrutura do PAC e aumento da taxa de juros Selic. No entanto, a política de rendas foi mantida, com novas elevações do salário-mínimo e a expansão da rede de proteção social e combate à pobreza.

Também foram adotadas medidas de contenção da expansão do crédito em segmentos específicos, como nos financiamentos para aquisição de veículos. Em consequência, o crédito cresceu menos ${ }^{6}$ e aumentou a inadimplência no total do crédito do sistema financeiro, que vinha em queda, chegando em 3,6\% em dezembro de $2011^{7}$.

Essa política monetária restritiva dificultou as condições de acesso financiamentos, tendo as instituições iniciado um aumento gradativo da seletividade na oferta de crédito para as famílias, principalmente no voltado à aquisição de veículos, para os quais foram exigidos maiores pagamentos de entrada.

As principais modalidades afetadas pela queda no ritmo de expansão do crédito foram

\footnotetext{
à população brasileira de baixa renda. A gestão é do Ministério das Cidades, tendo a Caixa Econômica Federal (CAIXA) como o órgão que financia e averigua as obras, além de regular os gastos dos empreendimentos e intermediar os financiamentos à população (Medida Provisória 459/2009).

5 Posteriormente, essa redução do IPI foi também ampliada para outros bens de consumo duráveis como eletrodomésticos (linha branca) e material de construção.

${ }^{6}$ Em 2011, as operações de crédito do sistema financeiro, incluídas as operações com recursos livres e direcionados, avançaram menos que em 2010, mas continuaram crescendo: $19 \%$ no ano, após altas de 15,2\% em 2009 e 20,6\% em 2010. Porém, a relação crédito/Produto Interno Bruto (PIB) cresceu, alcançando 49\% em 2011, ante $43,7 \%$ em 2009 e $45,2 \%$ em 2010.

${ }^{7}$ A inadimplência no total do crédito do sistema financeiro havia caído de 4,3\% em 2009 para 3,2\% em 2010, como mostram os dados dos Relatórios de Economia Bancária e Crédito do Banco Central.
} 


\section{INCLUSÃO FINANCEIRA E VULNERABILIDADE DO CONSUMIDOR DE CRÉDITO HABITACIONAL: UMA ANÁLISE JURÍDICO-ECONÔMICA DO MERCADO BRASILEIRO}

os financiamentos de veículos e o crédito pessoal, que cresceram bem menos $(23,5 \%$ e 19,2\% em 2011, respectivamente, ante $49,1 \%$ e $24,7 \%$ em 2010). Porém, o crédito para habitação continuou crescendo a taxas elevadas (44,5\% em 2011, um pouco menor que 45,2\% em 2009 e de $51,1 \%$ em 2010).

Esse crescimento deve-se ao fato de que os financiamentos habitacionais não foram atingidos por medidas restritivas e suas taxas de juros permaneceram baixas. Assim, o programa MCMV, ao praticar taxas de juros subvencionadas pelo governo federal impulsionou fortemente o financiamento de moradias para famílias de baixa renda. Também foram introduzidos incentivos à aquisição de bens duráveis por meio do programa Minha Casa Melhor (2013), destinado aos beneficiários do MCMV.

Em fins de 2014, o crédito imobiliário era a principal modalidade de crédito para as famílias, representando quase $1 / 3$ do crédito do SFN (31\%). Em ordem de importância vinham o consignado (18\%), o crédito para a aquisição de bens (14\%) e o cartão de crédito (11\%), conforme gráfico abaixo.

Gráfico 1 - Distribuição das principais modalidades de crédito pessoa física (2014)

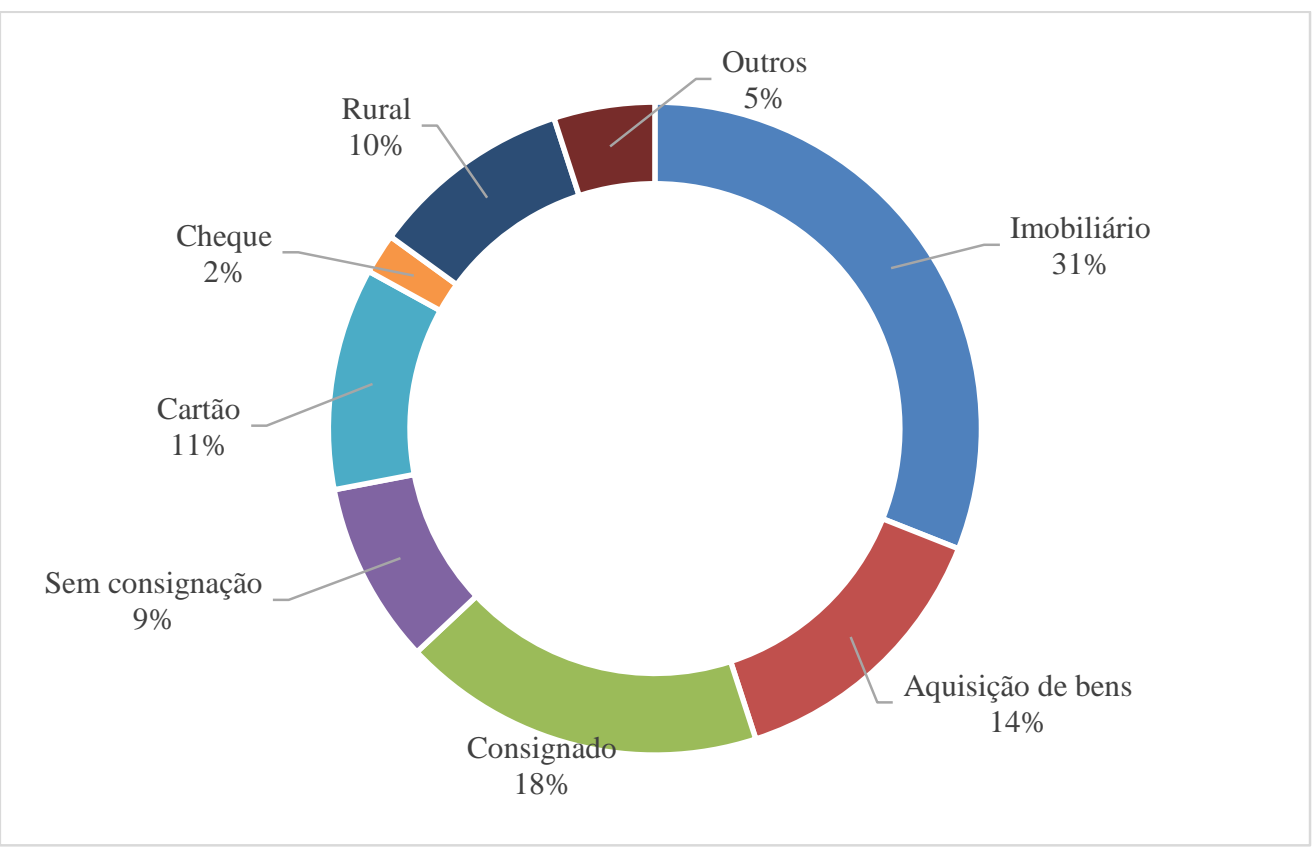

Fonte: Relatório de Inclusão Financeira do Banco Central (2015)

Dada a importância dessa modalidade, a seção a seguir mostra como o mercado de crédito habitacional tem se consolidado no Brasil, a partir de uma leitura consumerista sobre a 
vulnerabilidade do consumidor e da jurisprudência dos Tribunais Superiores.

\section{CRÉDITO, HABITAÇÃO E VULNERABILIDADE DO CONSUMIDOR DE CRÉDITO IMOBILIÁRIO: O SONHO DA CASA PRÓPRIA}

Com o crescimento das concessões de crédito no Brasil e as inovações da política habitacional brasileira, o mercado imobiliário experimentou um boom entre 2008 e 2013, marcado pela disseminação de novas incorporadoras e construtoras no âmbito da engenharia civil, indo na contramão da crise imobiliária dos Estados Unidos com relação às hipotecas, posto que, diferentemente desta, a economia nacional começou a dar sinais de prosperidade, destacando-se o mercado imobiliário, com expansão de vagas de trabalho e aquisição da primeira casa própria por muitos brasileiros.

Seguindo os dados do Banco Central do Brasil (BACEN), é possível perceber o comportamento do mercado de crédito brasileiro com relação ao volume de negócios e concessões de financiamento imobiliário para pessoas físicas (\% total entre taxas reguladas e taxas de mercado) entre março de 2011 e junho de 2017, período até a presente data disponível pelo sistema gerenciador de séries temporais do BACEN, in verbis:

Gráfico 2 - Concessões de financiamento imobiliário à pessoas físicas (taxas reguladas e taxas de mercado)

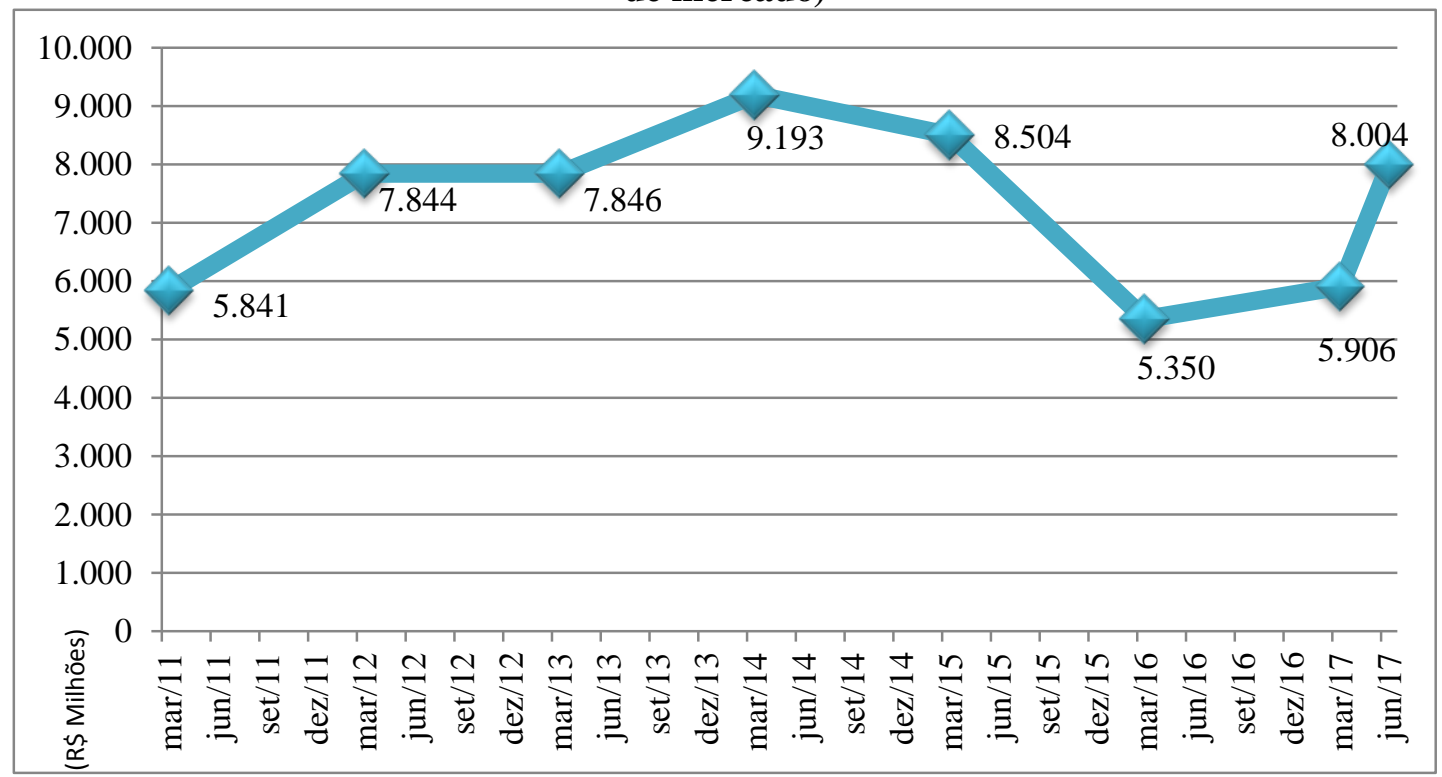

Fonte: BACEN - Sistema Gerenciador de Séries Temporais, 2017. 


\section{INCLUSÃO FINANCEIRA E VULNERABILIDADE DO CONSUMIDOR DE CRÉDITO HABITACIONAL: UMA ANÁLISE JURÍDICO-ECONÔMICA DO MERCADO BRASILEIRO}

Do gráfico em tela, a respeito do percentual total de concessões de crédito à pessoas físicas no Brasil de financiamento imobiliário, incluindo taxas reguladas e taxas de mercado, extrai-se que, até março de 2013, perpassando pelos anos de 2011 e 2012 neste mesmo mês, a economia brasileira e o sistema de crédito imobiliário vinha apresentando certa elevação e sinais de pleno aquecimento, demonstrando seu ápice por volta de março de 2014 com R\$ 9.183.000.000,00 (nove bilhões, cento e oitenta e três milhões de reais) em concessões de crédito nessa série.

A partir de então, o setor imobiliário começou a desaquecer, seja pela crise econômica brasileira a partir do ano de 2014 até a presente data, seja pelos elevados níveis de desemprego e férias coletivas dos trabalhadores, seja pela falência e recuperação judicial de inúmeras construtoras no país, a exemplo da PDG Realty Empreendimentos e Participações S/A, uma das maiores empresas de construção civil da América Latina, registrando no mês de março de 2016, um dos menores índices da série, totalizando $\mathrm{R} \$$ 5.350.000.000,00 (cinco bilhões, trezentos e cinquenta milhões de reais) em concessões de crédito no sistema imobiliário.

Essas informações são sensíveis para constatar a "corrida" dos consumidores brasileiros na realização de seus projetos de vida e também da conquista da casa própria, realidade até então inexistente para uma expressiva quantidade de famílias brasileiras que dependiam de aluguel ou habitavam na casa de parentes próximos e familiares de um modo geral.

Segundo dados do Instituto Brasileiro de Geografia e Estatística (IBGE), na Pesquisa Nacional por Amostras de Domicílios (PNAD) no ano de 2015, chegou-se a conclusão de que a maioria dos brasileiros tem domicílio próprio. Segundo a pesquisa, das condições de habitação, foram estimados 68,0 milhões de domicílios particulares permanentes no Brasil em 2015, o que representou um aumento de 998 mil unidades domiciliares em relação ao ano anterior, ou um crescimento de 1,5\%, consoante o Gráfico 3 aponta.

Revista de Direito, Globalização e Responsabilidade nas Relações de Consumo | e-ISSN: 2526-0030 | Maranhão | v. 3 | n. 2 | p. $43-61$ | Jul/Dez. 2017. 


\section{Gráfico 3 - Domicílios particulares permanentes}

Total e variação percentual por grandes regiões (2014-2015)

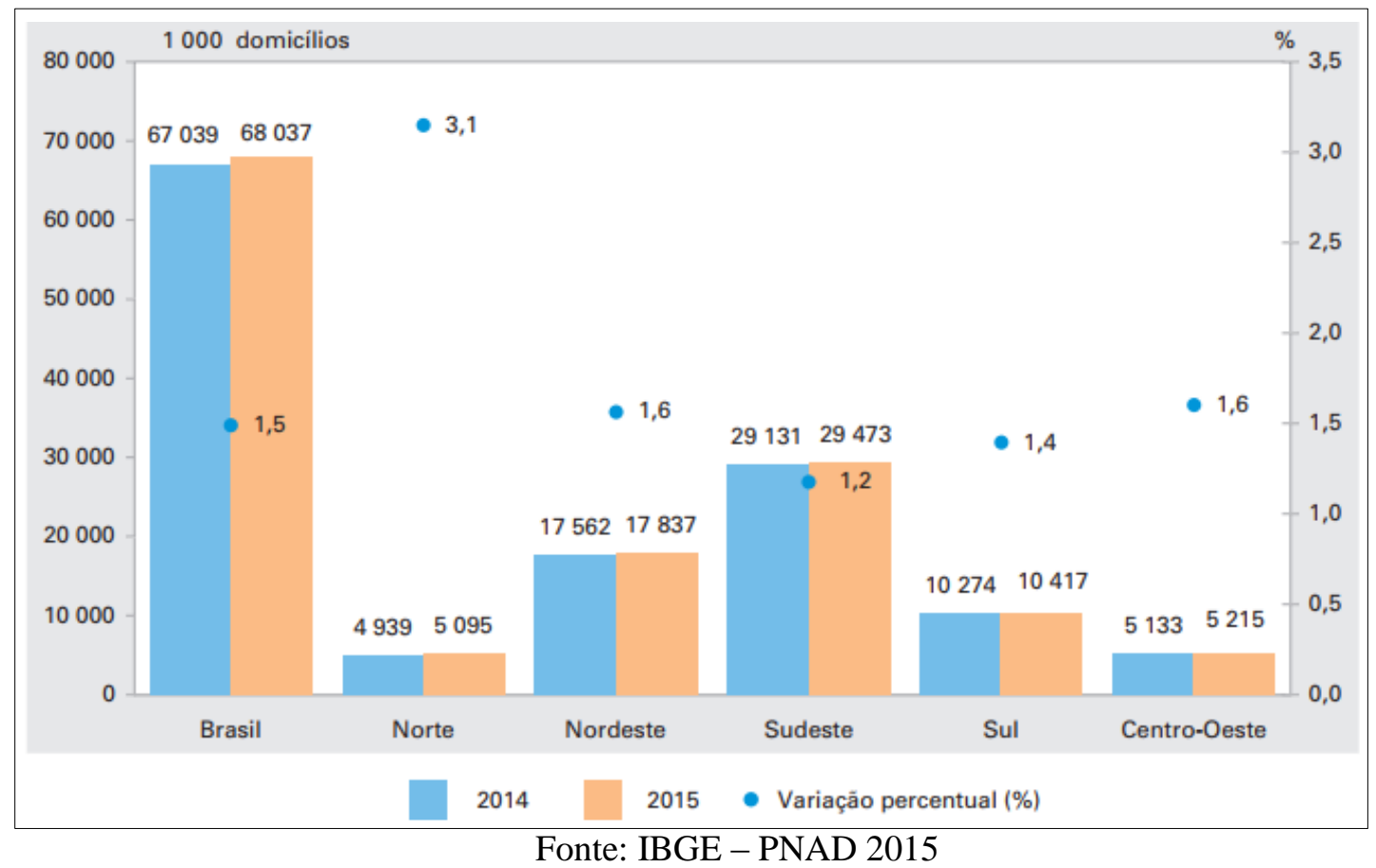

A Região Norte apresentou o maior aumento relativo no número de domicílios $(3,1 \%)$. As demais regiões assinalaram variações entre $1,2 \%$, na Sudeste, e 1,6\%, na Centro-Oeste e Nordeste. Em termos absolutos, as Regiões Sudeste e Nordeste registraram os maiores crescimentos, com 343 mil e 274 mil unidades domiciliares, respectivamente (Gráfico 3) do total de domicílios em 2015, 74,8\% eram próprios. Destes, 69,9\% já estavam quitados e 4,9\%, em aquisição. Em 2014, 73,7\% eram próprios, sendo 68,5\% quitados e 5,3\% em aquisição. Ao longo do período de 2004 a 2015, a proporção de domicílios próprios variou de 73,4\% (menor valor em 2006) a 74,8\% (em 2011, 2012 e 2015), como se visualiza no Gráfico 4.

Em termos absolutos, o total de domicílios próprios, no Brasil, aumentou em 1,5 milhão de unidades (3,0\%). Esse comportamento foi observado em todas as Grandes Regiões, especialmente na Norte $(5,0 \%)$. Os domicílios alugados, por sua vez, correspondiam a 17,9\% em 2015, proporção abaixo da estimada para 2014 (18,5\%), mas acima da verificada em 2004 (15,4\%, configurando um acréscimo de 2,5 pontos percentuais) (Gráfico 4).

Em termos absolutos, houve redução de 2,0\% de domicílios alugados no Brasil. Pela primeira vez, a série de dados mostra inversão da tendência de elevação dessa proporção desde 2004. Nas Regiões Sul e Centro-Oeste, no entanto, houve aumento (2,5\% e 1,7\%, respectivamente). 
Gráfico 4 - Percentual dos domicílios particulares permanentes, por condição de ocupação - Brasil (2004/2015)
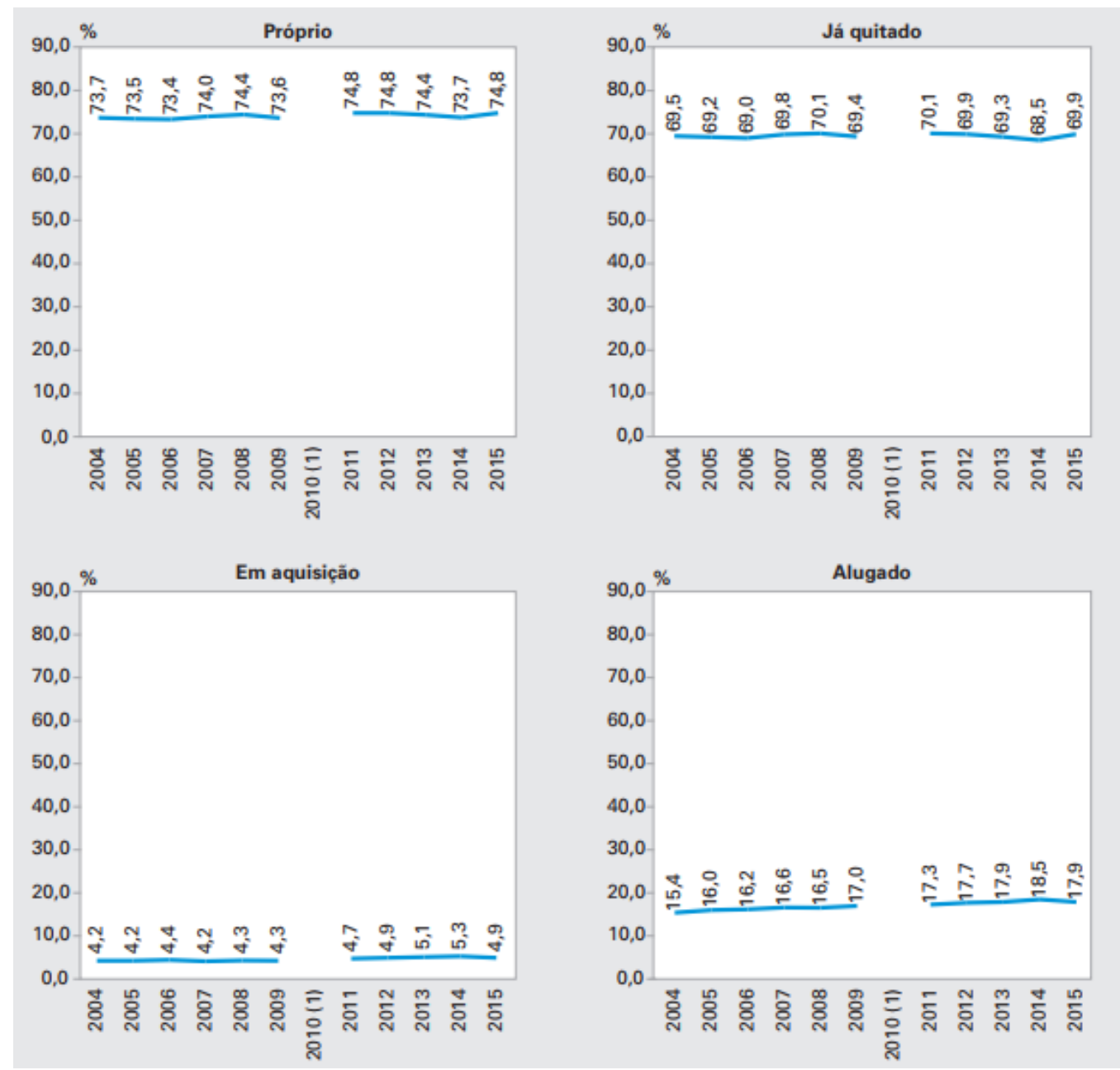

Fonte: IBGE - PNAD, 2015.

A receita perfeita para o assédio de consumo dos brasileiros que não tinham casa própria e da maximização dos lucros das instituições financeiras estava desenhada e pronta para ser executada. Um enorme volume de conteúdo publicitário, nunca antes visto no país com tanta frequência, instaurou-se em jornais, revistas, encartes, internet, rádio e televisão com estímulo à aquisição da casa própria.

Talvez por isso, acentuam Catalan e Pitol (2016), possa ser percebido o assédio, também, nas práticas que aliciem ou que seduzam - por meio da repetição - o consumidor e, em especial, mas não exclusivamente, o idoso, o analfabeto, o doente e todo aquele que, por qualquer outra razão, vivencie situação de vulnerabilidade extremada, buscando forçá-lo, constrangê-lo, aliciá-lo a adquirir produto, serviço ou obter acesso ao crédito, especialmente, 
por que "o simples fato de ver repetidamente um certo produto o torna mais desejável", como a casa própria.

Martins e Ramada (2014) destacam que o direito do consumidor à moradia cada vez mais está sendo afrontado pelas inúmeras práticas abusivas no mercado imobiliário, a exemplo da prática abusiva efetuada pelo agente financeiro, que condicionava a concessão do financiamento imobiliário à aquisição de seguro indicado pelo agente no contrato de mútuo, ocasião em que Superior Tribunal de Justiça (STJ) manifestou-se:

É necessária a contratação do seguro habitacional no âmbito do SFH. Contudo, não há obrigatoriedade de que o mutuário contrate o referido seguro diretamente com o agente financeiro ou com a seguradora indicada por este, exigência que configura venda casada, vedada pelo artigo 39, inciso I do CDC.

Em consequência, foi editada a Súmula 473 do STJ, segundo a qual "o mutuário do SFH não pode ser compelido a contratar o seguro habitacional obrigatório com a instituição financeira mutuante ou com a seguradora por ela indicada".

Outrossim, ainda hoje, argumentam os autores, o mercado imobiliário conta com inúmeras outras práticas abusivas efetivadas pelo fornecedor de serviços imobiliários. Basta verificar no boleto de cobrança de um imóvel administrado por uma imobiliária o repasse do valor do boleto bancário, de obrigação da imobiliária repassado para o consumidor, o que inclusive já fora repudiada tal prática por normativa ${ }^{8}$ específica.

Corroborando com o tema e identificando outra forma de abusividade, Marcelo Lima (2014) destaca que, tendo em vista a massificação dos contratos de adesão nas promessas de compra e venda de unidades autônomas, passou a ser comum a utilização de engenhosos mecanismos que oneram em demasia o adquirente.

Nesse contexto, não se pode deixar de olvidar que na medida em que o poder econômico oprime, o direito deve arcar com o ônus de libertar, de tirar as amarras que impedem o bom andamento da relação contratual. Nesta seara, merece destaque negativo a tentativa de transferência de custos da atividade empresarial aos adquirentes, por meio do repasse das comissões de corretagem e da questionável Assessoria Técnico-Imobiliária (SATI).

Analisando o tema por meio da sistemática de Recursos Repetitivos - Tema 938, o

\footnotetext{
${ }^{8}$ Norma Técnica no 777/2005 do Departamento de Proteção e Defesa do Consumidor (DPDC). Artigo $1^{\circ}$.
} 


\section{INCLUSÃO FINANCEIRA E VULNERABILIDADE DO CONSUMIDOR DE CRÉDITO HABITACIONAL: UMA ANÁLISE JURÍDICO-ECONÔMICA DO MERCADO BRASILEIRO}

STJ, quando analisou a validade da cláusula contratual que transfere ao consumidor a obrigação de pagar comissão de corretagem e taxa de assessoria técnico-imobiliária (SATI), posicionouse de maneira categoricamente contrária a princípios basilares do Código de Defesa do Consumidor, apesar de ter reconhecido a abusividade da taxa SATI, manteve a suposta legalidade da comissão de corretagem, desde que o consumidor seja previamente informado do preço total da aquisição da unidade autônoma, com o destaque do valor da comissão de corretagem (RESp 1599511/SP).

Essa posição, ratifica a imposição ao consumidor do pagamento da taxa de corretagem, o que é um absurdo, posto que, em nenhum momento o consumidor teve poder de ingerência na escolha da imobiliária, tampouco, poderá ser cobrado por algo que nunca contratou, uma vez que é de escolha unilateral da construtora, a eleição de seus parceiros comerciais, o que reforça, mais uma vez, a total ausência de ingerência do consumidor, destinatário final, nessa negociação, a ponto de ser cobrado pelos supostos serviços. O que há na verdade, é uma cristalina transferência do ônus financeiro e do risco da exploração da atividade econômica para o elo mais fraco, vulnerável e hipossuficiente da relação jurídica, no caso, o próprio consumidor.

Ademais, consoante destacam Zaban e Bessa (2015) em estudo empírico, extraem-se indicações preocupantes sobre a capacidade dos consumidores brasileiros compreenderem finanças e tomarem decisões adequadas financeiramente, o que pode ser resumido nas seguintes observações iniciais sobre consumidores interessados em imóveis: a) Não sabem dizer o que é a inflação atual; b) Preferem antecipar pagamentos mesmo quando a antecipação é financeiramente desvantajosa; c) Tem dificuldades em calcular juros compostos ao longo do tempo (potencialmente tem dificuldades até mesmo de cálculos juros simples); d) Demonstram saber que juros aumentam valores ao longo do tempo; e) Maior escolaridade possui algum efeito sobre maior conhecimento sobre inflação, mas em termos absolutos o conhecimento é reduzido em todas as faixas de escolaridade; f) Não usam suas próprias perspectivas sobre a inflação para tomar decisões financeiras; g) Não há correlação expressiva entre a idade e perspectiva sobre a inflação.

Tudo isto, segundo os pesquisadores responsáveis pelo estudo, sugere a necessidade de cautela na avaliação de decisões financeiras por consumidores. O consumidor pode não ter o conhecimento geral sobre elementos financeiros cruciais à tomada de decisão, tais como inflação. Ele pode não ser capaz de processar a informação disponível para chegar à decisão 
mais vantajosa para si do ponto de vista financeiro. A relevância destas constatações para o direito do consumidor e para a política de defesa deste é evidente. Redações de cláusulas contratuais e práticas empresariais devem ser elaboradas e avaliadas à luz do que se sabe sobre o comportamento real do consumidor. Para empresas, saber da deficiência do consumidor na tomada de decisão é fundamental para evitar conflitos no futuro e reduzir os riscos do negócio. Para o sistema de proteção ao consumidor, entender em que pontos os consumidores tendem a cometer erros pode viabilizar intervenções bem focalizadas para o aprimoramento de decisões.

Não ser quer, com isso, dizer que a concessão de crédito imobiliário, como visto acima, represente um perigo às relações jurídicas de consumo, muito pelo contrário, sem crédito, milhões de famílias brasileiras não teriam acesso à aquisição da casa própria. O que se almeja, é o reconhecimento da vulnerabilidade do consumidor nesse tipo de relação jurídica de consumo, seja ela econômica, seja ela psíquica, na busca da tão sonhada casa própria, de modo que o direito do consumidor, assim como os tribunais brasileiros estejam concatenados à essa nova realidade jurídico-econômica do mercado de crédito imobiliário, atendendo, assim, à base principiológica do CDC, bem como dos direitos básicos dos consumidores, entre eles, a proteção contra a publicidade enganosa e abusiva, métodos comerciais coercitivos ou desleais, bem como contra práticas e cláusulas abusivas ou impostas no fornecimento dos produtos ou serviços.

Nesse sentido, também o resgate da ideologia inicialmente concebida no CDC quanto à Política Nacional das Relações de Consumo, garantindo-se a harmonização dos interesses dos participantes das relações de consumo e compatibilização da proteção do consumidor com a necessidade de desenvolvimento econômico e tecnológico, de modo a viabilizar os princípios nos quais se funda a ordem econômica, sempre com base na boa-fé e equilíbrio nas relações entre consumidores e fornecedores.

\section{CONSIDERAÇÕES FINAIS}

$\mathrm{Na}$ última década, o crédito e o acesso aos serviços financeiros aumentaram consideravelmente. Os financiamentos imobiliários foram responsáveis por expressiva parte desse crescimento, chegando, em 2014, a representar a principal modalidade de crédito para as famílias e $31 \%$ dos empréstimos do sistema financeiro brasileiro.

Nesse período, a política habitacional incentivou a construção civil e, com a 


\section{INCLUSÃO FINANCEIRA E VULNERABILIDADE DO CONSUMIDOR DE CRÉDITO HABITACIONAL: UMA ANÁLISE JURÍDICO-ECONÔMICA DO MERCADO BRASILEIRO}

implementação do Programa Minha Casa Minha Vida (PMCMV), em 2009, muitas famílias de baixa renda foram estimuladas a realizar o sonho da casa própria.

O acesso e o uso desses serviços e produtos são importantes dimensões da inclusão financeira que, por sua vez, deve também considerar a qualidade, a relevância dos serviços e produtos financeiros para a vida do consumidor. Ou seja, tão importante quanto a disponibilidade de serviços e produtos financeiros e a extensão de sua utilização é a qualidade, a relevância desses para a qualidade de vida das pessoas.

Dados do Relatório de Inclusão Financeira do Banco Central mostram que, em 2014, mais de 130 milhões de pessoas da população adulta mantinham algum relacionamento bancário, como contas de depósitos a vista, contas de depósitos de poupança e contas-correntes de depósitos para investimento. Com mais acesso e uso, associado à ampliação da disponibilidade de crédito, o endividamento das famílias cresceu entre 2007 e 2014 de $29 \%$ para $46 \%$ da renda disponível.

Expressiva parte desse endividamento (18\% em 2014) é de crédito imobiliário, que havia aumentado $229 \%$ entre 2010 e 2014, refletindo a combinação de uma forte demanda criada pelo déficit habitacional existente no país com juros baixos e outras facilidades impulsionadas pela política econômica e social do período, notadamente do programa MCMV, com taxas de juros subvencionadas pelo Governo Federal, direcionado ao financiamento de moradias para famílias de baixa renda.

É indiscutível que há maior acesso da população ao sistema financeiro no Brasil, dada a quantidade de pontos de atendimento e sua capilaridade. Quanto ao uso dos serviços financeiros pelos clientes, os dados também evidenciam uma grande abrangência. Mas e a qualidade? Para que essa inclusão não se limite à bancarização, é preciso que o uso dos serviços bancários, antes inacessíveis, viabilize a melhora da qualidade de vida desses consumidores. Quer dizer, é preciso que aqueles que não tinham acesso a serviços financeiros e, agora os têm, sejam beneficiados pelos três pilares da cidadania financeira - a inclusão, a educação e a proteção.

O reconhecimento da vulnerabilidade do consumidor de crédito, em especial, do crédito habitacional, responsável pela realização do sonho da casa própria de muitos brasileiros, é por si só, agravado. Isso reclama do direito e, em especial, dos tribunais brasileiros, maior zelo na interpretação e aplicação do microssistema jurídico de consumo, de modo que, cada vez menos, tenhamos interpretações equivocadas à respeito da proteção do consumidor, vulnerável 
e hipossuficiente por natureza, como no caso do STJ no julgamento do Recurso Repetitivo Tema 938, o que representou uma verdadeira involução da esfera protetiva no âmbito das relações de consumo.

É preciso que o sonho das pessoas não alimente ou seja alvo de extorsão do capital das instituições financeiras e construtoras. O crédito tomado precisa ter qualidade, ter transparência, uma dimensão fundamental da cidadania financeira. Assim, faz-se necessário, sobretudo, ampliar o respeito para com o consumidor, e, certamente, construir uma atuação concatenada do Estado na coibição de ilícitos de consumo e práticas abusivas perpetradas no âmbito desse nicho do mercado, apelando para o efeito pedagógico na correção de eventuais cláusulas ou práticas entendidas como abusivas e levadas a efeito por esses fornecedores.

\section{REFERÊNCIAS}

BARBOSA, Nelson. Dez anos de política econômica. In: SADER, Emir. 10 anos de governos pós-neoliberais no Brasil: Lula e Dilma. São Paulo: Boitempo; Rio de Janeiro: FLACSO Brasil, 2013.

BELUZZO, Luiz Gonzaga. Os anos do povo. IN: SADER, Emir. 10 anos de governos pósneoliberais no Brasil: Lula e Dilma. São Paulo: Boitempo; Rio de Janeiro: FLACSO Brasil, 2013, p. 103-110. Disponível em http://www.flacso.org.br/. Acesso em 13 maio.2017.

BRESSER-PEREIRA, Luiz Carlos. O novo desenvolvimentismo e a ortodoxia convencional. São Paulo em Perspectiva, vol. 20, n 3, p. 5-24, julho-setembro 2006.

CATALAN, Marcus Jorge; PITOL, Yasmine Uequed. Primeiras Linhas Acerca do Tratamento Jurídico do Assédio de Consumo no Brasil. In: Direito, Globalização e Responsabilidade nas Relações de Consumo. Florianópolis: CONPEDI, 2016.

INSTITUTO BRASILEIRO DE GEOGRAFIA E ESTATÍSTICA (IBGE). Pesquisa Nacional por Amostras de Domicílios - 2015. Disponível em: www.ibge.gov.br. Acesso em: 10 ago 2017.

LOUREIRO, Eleonora; MADEIRA, Gabriel; BADER, Fani. Expansão dos Correspondentes Bancários no Brasil: Uma análise empírica. Texto para discussão n. 433. Brasília: Banco Central do Brasil, 2016. Disponível em http://www.bcb.gov.br/pec/wps/port/wps433.pdf. Acesso em 1 de agosto de 2017.

MARTINS, Plínio Lacerda; RAMADA, Paula Cristiane Pinto. Overbooking Imobiliário e os Direitos do Consumidor na Aquisição de Imóveis. In: Revista de Direito do Consumidor. (Coord. Cláudia Lima Marques). Vol. 91. São Paulo: Revista dos Tribunais, 2014. 
MATTEI, Lauro. Gênese e agenda do novo desenvolvimentismo brasileiro. IN: Revista de Economia Política, vol. 33, nº 1 (130), pp. 41-59, 2013.

MATTOSO, Jorge. Dez anos depois. IN: SADER, Emir. 10 anos de governos pós-neoliberais no Brasil: Lula e Dilma. São Paulo: Boitempo; Rio de Janeiro: FLACSO Brasil, 2013, p. 111122. Disponível em http://www.flacso.org.br/. Acesso em 13 maio.2017.

OLIVEIRA, Felipe Guimarães de. O Superendividamento na sociedade brasileira e os desafios para uma tutela jurídico-econômica de proteção ao consumidor no século XXI. Dissertação de Mestrado. Centro Universitário do Estado do Pará (CESUPA), 2016.

REYMÃO, Ana Elizabeth Neirão; OLIVEIRA, Felipe Guimarães de. O Superendividamento do Consumidor no Brasil: Um Debate Necessário entre o Direito e a Economia no Século XXI. IN: Congresso Nacional do Conpedi, XXV, Brasília, 2016. Anais. Brasília: Conpedi, 2016, p. 23-43.

RIBEIRO, Rodrigo Fernandes. LARA, Ricardo. O endividamento da classe trabalhadora no Brasil e o capitalismo manipulatório. In: Serviço Social e Sociedade, São Paulo, n. 126, p. 340$359,2016$.

SADER, Emir. A construção da hegemonia pós-neoliberal. In SADER, Emir (org). 10 anos de governos pós-neoliberais no Brasil: Lula e Dilma. São Paulo, SP: Boitempo; Rio de Janeiro: FLACSO Brasil, 2013, p. 135-143. Disponível em http://www.flacso.org.br/. Acesso em 13 maio.2017.

SICSU, João.; PAULA, Luiz Fernando de; MICHEL, Renaut. Novo-Desenvolvimentismo: Um Projeto Nacional de Crescimento com Equidade Social. Rio de Janeiro: Manole, 2005.

SICSÚ, João; CASTELAR, Armando (org.). Sociedade e economia: estratégias de crescimento e desenvolvimento. Brasília: IPEA, 2009.

ZABAN, Breno; BESSA, Leonardo Roscoe. Vulnerabilidade do Consumidor: Estudo Empírico sobre a Capacidade de Tomada de Decisões Financeiras por Interessados na Compra de Imóveis. IN: Revista de Direito do Consumidor. (Coord. Cláudia Lima Marques). Vol. 101. São Paulo: Revista dos Tribunais, 2015, p. 98. 